\title{
Intrinsic and Extrinsic Contributions to Auditory Selectivity in a Song Nucleus Critical for Vocal Plasticity
}

\author{
Merri J. Rosen and Richard Mooney \\ Department of Neurobiology, Duke University Medical Center, Durham, North Carolina 27710
}

\begin{abstract}
The development, maintenance, and perception of learned vocalizations in songbirds are likely to require auditory neurons that respond selectively to song. Neurons with song-selective responses have been described in several brain nuclei critical to singing, but the mechanisms by which such response properties arise, are modified, and propagate are poorly understood. The lateral magnocellular nucleus of the anterior neostriatum (LMAN) is the output of an anterior forebrain pathway (AFP) essential for learning and maintenance of song, processes dependent on auditory feedback. Although neurons throughout this pathway respond selectively to auditory presentation of the bird's own song, LMAN is the last stage at which responses to this auditory information could be transformed before being transmitted to vocal motor areas, where such responses may influence vocal production. Indeed, previous extracellular studies have indicated that LMAN's auditory selectivity is greater than that at earlier
\end{abstract}

stages of the AFP. To determine whether LMAN local circuitry transforms or simply relays song-related auditory information to vocal control neurons, it is essential to distinguish local from extrinsic contributions to LMAN's auditory selectivity. In vivo intracellular recordings from LMAN projection neurons, coupled with local circuit inactivation, reveal that much of LMAN's song selectivity is supplied by its extrinsic inputs, but selective blockade of GABA receptors indicates that local inhibition is required for the expression of song selectivity. Therefore, LMAN neurons receive highly song-selective information, but LMAN's local circuitry can mask these selective inputs, providing a mechanism for context-dependent auditory feedback.

Key words: auditory selectivity; song selectivity; birdsong; zebra finch; LMAN; in vivo; intracellular; local circuitry; inactivation; GABA; bicuculline
Auditory responses selective for communication sounds exist in neurons of many vertebrates, including primates, bats, frogs, and songbirds (Narins and Capranica, 1976; Margoliash, 1983; Rauschecker et al., 1995; Esser et al., 1997). Neurons selective for birdsong are among the most well characterized of these and are widely distributed in songbird brain nuclei that are important for song production and development (Margoliash, 1983; Williams and Nottebohm, 1985; Doupe and Konishi, 1991; Vicario and Yohay, 1993; Janata and Margoliash, 1999). How this selectivity is generated, transformed, and/or transmitted by any of these nuclei is poorly understood. Such knowledge can illuminate how song is represented in the auditory domain in circuits in which it could influence vocal learning and perception.

The neural substrate for singing comprises a vocal motor pathway (VMP) used throughout life and an anterior forebrain pathway (AFP) needed for juvenile song development and, in some species, auditory maintenance of adult song (Fig. 1A) (Nottebohm et al., 1976; Bottjer et al., 1984; McCasland, 1987; Simpson and Vicario, 1990; Williams and Mehta, 1999; Brainard and Doupe, 2000). The VMP includes HVc (used as a formal name), the robust nucleus of the archistriatum (RA), respiratory areas, and hypoglossal motoneurons innervating the syrinx (Vicario, 1991; Wild, 1993a,b). The AFP indirectly links HVc to RA, via area X, the dorsolateral part of the medial thalamus (DLM), and the lateral magnocellular nucleus of the anterior neostriatum (LMAN) (Okuhata and Saito, 1987; Bottjer et al., 1989). Ultimately RA vocal premotor neurons receive input from $\mathrm{HVc}$ and LMAN axons, providing a cellular

Received Nov. 23, 1999; revised April 17, 2000; accepted April 17, 2000

This research was supported by National Institutes of Health Grant R01 DC 02524 and by McKnight, Klingenstein, and Sloan Foundation awards to R.M. We thank T. Tucker, D. Feldman, D. Fitzpatrick, and members of the Mooney lab for providing thoughtful comments on previous versions of this manuscript and Dr. Jose Manuel Alonso for helpful suggestions concerning GABA inactivation.

Correspondence should be addressed to Dr. Richard Mooney, Department of Neurobiology, Box 3209, Duke University Medical Center, Durham, NC 27710. E-mail: mooney@neuro.duke.edu.

Copyright (C) 2000 Society for Neuroscience $0270-6474 / 00 / 205437-12 \$ 15.00 / 0$ site where these pathways could interact to influence singing (Canady et al., 1988; Mooney and Konishi, 1991). All of these forebrain nuclei contain neurons that are song selective, responding more strongly to auditory presentation of the bird's own song (BOS playback) than to other songs or nonsong stimuli.

LMAN's auditory nature is of special interest because this nucleus is strongly implicated in auditory processes essential to the development, adult maintenance, and perception of song (Price, 1979; Nordeen and Nordeen, 1992; Scharff et al., 1998; Leonardo and Konishi, 1999). A purported role for LMAN is to provide auditory feedback to the VMP for vocal error correction, because LMAN lesions prevent deafening-induced song degradation (Brainard and Doupe, 2000). LMAN is the last stage at which auditory information could be transformed before influencing the VMP, and within-bird auditory response comparisons across the AFP indicate that LMAN may refine less-selective inputs. For example, area $\mathrm{X}$ neurons more frequently respond to noise stimuli than do LMAN neurons (Doupe, 1997), suggesting hierarchical refinement along the AFP, similar to that described in other sensory systems (Konishi et al., 1988; Livingstone and Hubel, 1988). In songbirds, the heightened selectivity afforded by such refinement could enable greater precision in vocal error correction. Alternatively LMAN's afferents may already be highly selective, and LMAN may simply relay this information to $\mathrm{RA}$. In either case, detecting any auditory transformations within LMAN requires distinguishing extrinsic from intrinsic contributions to the auditory selectivity of LMAN neurons that innervate RA. Therefore, we combined in vivo intracellular recordings from LMAN neurons with auditory stimulation and used reversible inactivation to compare song-evoked responses with and without local circuit activity.

\section{MATERIALS AND METHODS}

Subjects. Experiments used adult [95-440 posthatch days (PHD)] male zebra finches (Taeniopygia guttata) in accordance with a protocol approved by the Duke University Institutional Animal Care and Use Committee. Birds were bred and raised in our colony, housed with their parents until $40 \mathrm{PHD}$, and then moved into holding cages of six to eight birds. 


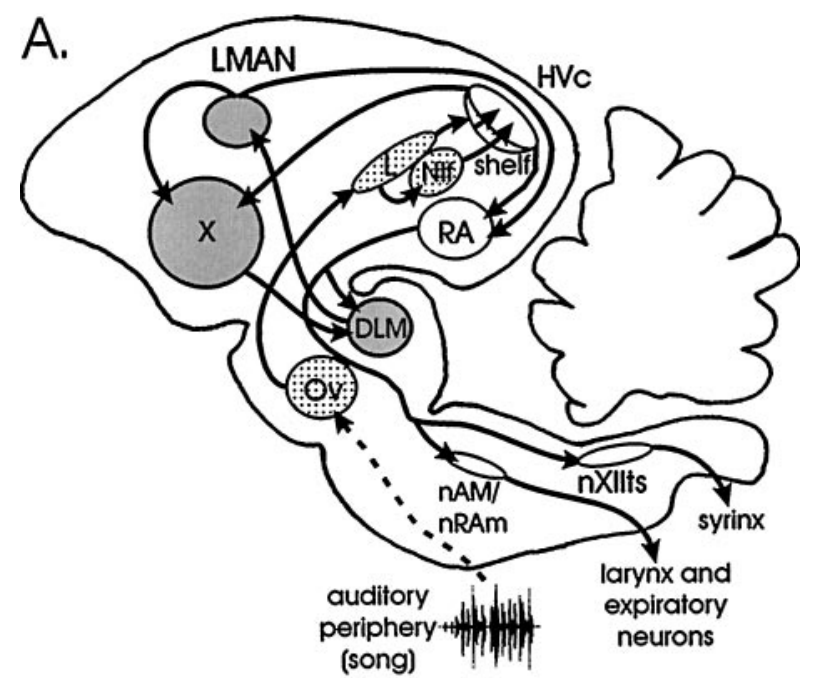

B.

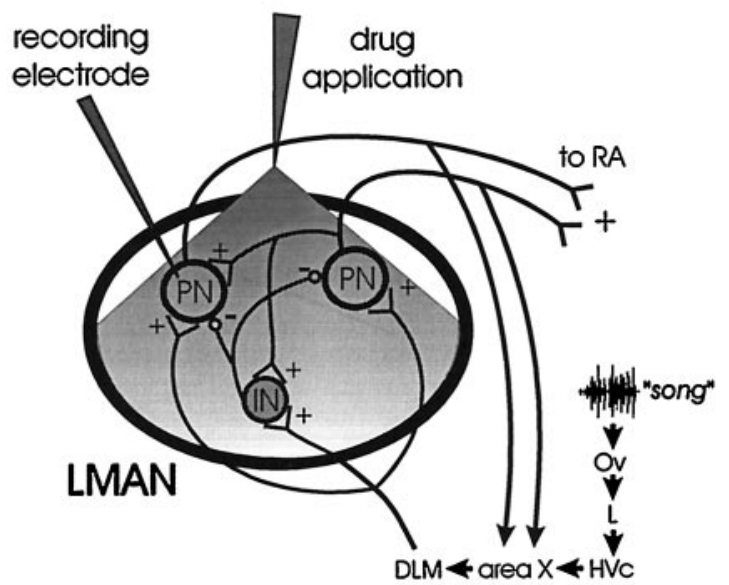

Figure 1. Schematics of the song circuit and LMAN. A, The VMP (white) used in singing includes $\mathrm{HVc}, \mathrm{RA}$, nAM, the vocal motoneurons in nXIIts, and respiratory premotor neurons in $\mathrm{nAM}$ and $\mathrm{nRAm}$. The AFP (gray) used in auditory-dependent song development as well as in adult song maintenance includes area X, DLM, and LMAN. Auditory areas presynaptic to $\mathrm{HVc}$ include $\mathrm{Ov}$, field $\mathrm{L}$, and $\mathrm{NIf}$ (dotted); the dashed line indicates abbreviated ascending auditory structures. $B$, The diagram of LMAN's intrinsic and extrinsic connections shows the experimental protocol. LMAN contains projection neurons $(P N)$ that innervate area $\mathrm{X}$ and RA and GABAergic interneurons $(I N)$ that innervate these projection neurons; both cell classes receive excitatory input from DLM and other LMAN projection neurons. Intracellular recordings were made from LMAN projection neurons while delivering auditory stimuli ("song"). In some experiments, $\mathrm{GABA}_{\mathrm{A}}$ receptor antagonists or GABA were applied to LMAN via a puffer pipette positioned immediately dorsal to the nucleus. DLM, Dorsolateral part of the medial thalamus; $H V C$ (used as a proper name); $L$, field $\mathrm{L} ; L M A N$, lateral magnocellular nucleus of the anterior neostriatum; $n A M$, nucleus ambigualis; NIf, nucleus interfacialis; $n R A m$, nucleus retroambigualis; $n X I I t s$, tracheosyringeal portion of the hypoglossal nucleus; $O v$, nucleus ovoidalis; $R A$, robust nucleus of the archistriatum; $X$, area $\mathrm{X}$.

Stimuli. Before the experiment, song was recorded from birds placed in a small recording chamber (Industrial Acoustics, Bronx, NY) with an adult female to induce them to sing. Songs were recorded and edited with LabView software (National Instruments, Austin, TX; all custom software for this study was written by M. Rosen, F. Livingston, R. Neumann, and R. Balu). Amplified vocalizations from a microphone were low-pass filtered at $10 \mathrm{kHz}$, digitized at $20 \mathrm{kHz}$ (National Instruments data acquisition board AT-MIO-16E2), and stored on a personal computer (PC). Edited songs included either one or two exemplary motifs. Presented stimuli always included the BOS, reversed-syllable BOS (e.g., syllables ABCD presented as DCBA, perturbing global but not local temporal information), and reversed BOS (i.e., song played backward, perturbing local and globa temporal order, while maintaining spectral information). Conspecific (an- other adult male) and heterospecific (male Bengalese finch) song and white noise (a Gaussian-distributed pseudorandom sequence) often were also presented. Stimuli were 1-3 sec in duration.

Preparatory surgery. Two days before electrophysiological recording, birds were food and water deprived for $1 \mathrm{hr}$, injected intramuscularly with equithesin $(2 \mathrm{mg} / \mathrm{kg}$, i.m.: $0.85 \mathrm{gm}$ of chloral hydrate, $0.21 \mathrm{gm}$ of pentobarbitol, $0.42 \mathrm{gm}$ of $\mathrm{MgSO}_{4}, 2.2 \mathrm{ml}$ of $100 \%$ ethanol, and $8.6 \mathrm{ml}$ of propylene glycol brought to a $20 \mathrm{ml}$ final volume with $\mathrm{dH}_{2} \mathrm{O}$ ), and placed in a stereotaxic device $\left(45^{\circ}\right.$ head angle; $\mathrm{H}$. Adams, California Institute of Technology). Lidocaine $(2 \% ; 20 \mu l)$ was injected subcutaneously, and the scalp was dissected along the midline. LMAN's location was marked using stereotaxic coordinates $(5.15 \mathrm{~mm}$ rostral and $1.75 \mathrm{~mm}$ lateral from the bifurcation of the midsagittal sinus). A stainless steel post was mounted to the caudal skull with dental cement, the wound was closed with cyanoacrylate, antibiotic was applied, and the bird was kept warm $\left(33^{\circ} \mathrm{C}\right)$ until recovery $(2-4 \mathrm{hr})$.

In vivo electrophysiology, song presentation, and drug application. Immediately before electrophysiological recording, birds were injected intramuscularly with $20 \%$ urethane in $\mathrm{dH}_{2} \mathrm{O}(75-100 \mu \mathrm{l}$ total; Sigma, St. Louis, MO) in $25 \mu \mathrm{l}$ doses at 30 min intervals. Urethane does not suppress neural activity and has been used in previous studies for extracellular characterization of song selectivity in LMAN (Doupe and Konishi, 1991). Birds were immobilized via the mounted post in a sound-attenuating chamber on an air table (Technical Manufacturing Corporation, Peabody, MA); temperature was maintained via an electric blanket at $39^{\circ} \mathrm{C}$ (Harvard Apparatus, Holliston, MA). The scalp was retracted, a small craniotomy $(<500$ $\mu \mathrm{m}$ ) was made over LMAN, and the dura was removed.

Sharp electrodes (borosilicate glass, BF100-50-10; Sutter Instrument, Novato, CA) were pulled to $60-125 \mathrm{M} \Omega$ when filled with $3 \mathrm{M}$ K-acetate (or in some cases $3 \mathrm{M}$ Cs-acetate), $5 \%$ neurobiotin (for histological reconstruction), and in some cases $100 \mathrm{~mm}$ QX-314 (a Na ${ }^{+}$channel blocker; Research Biochemicals, Natick, MA). A hydraulic microdrive (Soma Scientific, Irvine, CA) was used to lower electrodes to the nucleus $(\sim 2000 \mu \mathrm{m})$. An AxoClamp 2B intracellular amplifier (Axon Instruments, Foster City, $\mathrm{CA}$ ) used in bridge mode recorded intracellular potentials, which were low-pass filtered at $3 \mathrm{kHz}$, digitized at $10 \mathrm{kHz}$, and stored on a PC. LMAN neurons were identified on-line by their characteristic spike shape and firing patterns (see Livingston and Mooney, 1997) and later verified histologically. Cells were tested with auditory stimuli if their resting potentials were negative of $-60 \mathrm{mV}$ and robust spontaneous synaptic activity was present. In some cases, input resistances and responses to current pulse injections were collected; both instantaneous and mean (over the 1 sec current pulse) firing rates were calculated in response to depolarizing currents. All values are reported as the mean \pm SEM.

Ten to thirty iterations of each auditory stimulus, delivered at intervals ranging from 7 to $11 \mathrm{sec}$, were presented at $\sim 70 \mathrm{~dB}$ (rms; A-weighting) through a speaker $20 \mathrm{~cm}$ behind the bird. Peristimulus time histograms (PSTHs; $25 \mathrm{msec}$ bin width) and median-filtered averaged membrane potential traces (see below) were computed on-line to allow immediate assessment of the responsiveness to the various auditory stimuli and to aid in experimental decisions. As noted in the results for certain cells, tonic negative or positive currents were injected through the recording electrode to shift the resting membrane potential of the cell.

For pharmacological experiments, a second micropipette [10-20 $\mu \mathrm{m}$ tip; filled with $250 \mathrm{~mm}$ GABA (Research Biochemicals) or $5 \mathrm{~mm}$ bicuculline methiodide (Sigma) in $0.9 \%$ saline] was lowered through a second craniotomy to a point slightly dorsolateral to LMAN. Drugs were pressureejected with a Picospritzer (General Valve, Fairfield, NJ) in 10-200 msec pulses at 40 psi. For bicuculline treatment, which took 30-90 min to wash out, the pressure pipette was removed after drug application. After bicuculline application, LMAN neurons exhibited rhythmic bursting behavior that was used to assess the drug's effect in subsequent recordings (see Fig. 6). GABA was applied during interstimulus intervals while recording, because it washed out very quickly $(10-120 \mathrm{sec})$. Effectiveness of the GABA inactivation was assessed during and after the application period by monitoring changes in spontaneous PSP amplitude, as well as by monitoring the ability of a positive current pulse to evoke action potentials.

Data analysis. The suprathreshold responsiveness $\left(R_{\text {FiringRate }}\right)$ of cells with spiking activity was calculated by $R_{\text {FiringRate }}=S_{\mathrm{FR}}-B_{\mathrm{FR}}$, where $S_{\mathrm{FR}}$ and $B_{\mathrm{FR}}$ are the firing rates during each stimulus presentation and during a $1.0-1.5 \mathrm{sec}$ baseline period before each stimulus presentation, respectively. To assess subthreshold responsiveness in spiking cells, raw traces were first median-filtered (each point replaced by the median value of the surrounding 50 points, equivalent to $5 \mathrm{msec}$ at our sample rate of $10 \mathrm{kHz}$ ); this removes very high-frequency events such as action potentials (which are $\sim 1 \mathrm{msec}$ in duration) and thus reduces action potential contamination of subthreshold changes in membrane potential [for an example, see Jagadeesh et al. (1997), their Fig. 1]. The subthreshold responsiveness $\left(R_{\text {area }}\right)$ of both nonspiking and median-filtered spiking cells was measured by $R$ area $=S_{\text {area }}-B_{\text {area }}$, where $S_{\text {area }}$ and $B_{\text {area }}$ are the integrals of the positive-going deviations in $\mathrm{V}_{m}$ from the mode of the baseline period (which gave a more reliable estimate of the $\mathrm{V}_{m}$ than did either the median or the mean) during and before stimulus presentation, respectively. (This method also detected stimulus-induced hyperpolarization in $\mathrm{V}_{m}$, when positive-going deviations from the mode are larger during baseline than during stimulus, but tended to underestimate the amplitude of the hyper- 
polarization.) Average $R_{\text {FiringRate }}$ or $R_{\text {area }}$ was computed for 10-30 iterations of stimuli.

To compare suprathreshold and subthreshold responses, response strengths were expressed as z-scores. The suprathreshold z-score $\left(Z_{\mathrm{Firin}}\right.$ gRate) is given by the difference between the average firing rate during stimulus presentation and that during a $1.0-1.5 \mathrm{sec}$ baseline period before stimulus presentation, divided by the SD of this difference:

$$
Z_{\text {FiringRate }}=\frac{\bar{S}_{\mathrm{FR}}-\bar{B}_{\mathrm{FR}}}{\sqrt{\operatorname{Var}\left(S_{\mathrm{FR}}\right)+\operatorname{Var}\left(B_{\mathrm{FR}}\right)-2 \operatorname{Covar}\left(S_{\mathrm{FR}}, B_{\mathrm{FR}}\right)}}
$$

where $\bar{S}_{\mathrm{FR}}$ is the mean firing rate during the stimulus, $\bar{B}_{\mathrm{FR}}$ is the mean firing rate during the baseline period, and the denominator is the SD of $S_{\mathrm{FR}}-B_{\mathrm{FR}}$. For nonspiking cells and median-filtered spiking cells, the subthreshold z-score $\left(Z_{\text {area }}\right)$ is given by the difference between the average area during stimulus presentation and that during baseline, divided by the $\mathrm{SD}$ of this difference. The $Z_{\text {area }}$ formula is the same as that for $Z_{\text {FiringRate }}$ with substitutions of ${ }_{\text {area }}$ for ${ }_{F R}$, where $\bar{S}_{\text {area }}$ is the mean deviation in $\mathrm{V}_{m}$ (from the baseline mode) during song presentation and $\bar{B}_{\text {are }}$ is the mean deviation in $\mathrm{V}_{m}$ during baseline; the denominator is the $\mathrm{SD}$ of $S_{\text {area }}$ $B_{\text {area }}$

To quantify each neuron's response strength, the psychophysical measure $d^{\prime}$ (Green and Swets, 1966), which represents the discriminability between two stimuli, was used to compare BOS with reversed-BOS responses. A difference in response to these two stimuli has been used previously as the criterion for selectivity of neurons in LMAN, as well as in HVc (Solis and Doupe, 1997; Theunissen and Doupe, 1998). The $d^{\prime}$ value for the discriminability of the response to BOS versus that to reversed BOS was calculated as:

$$
\mathrm{d}_{\text {FiringRate }}^{\prime}=\frac{2\left(\bar{R}_{\text {FRвos }}-\bar{R}_{\text {FR rev }}\right)}{\sqrt{\sigma^{2} \text { BOS }+\sigma^{2} \text { rev }}} \text { or } \mathrm{d}_{\text {area }}^{\prime}=\frac{2\left(\bar{R}_{\text {areaвos }}-\bar{R}_{\text {arearev }}\right)}{\sqrt{\sigma^{2} \text { BOS }+\sigma^{2} \text { rev }}}
$$

where $d_{\text {FiringRate }}^{\prime}$ represents suprathreshold responsiveness and $d^{\prime}$ area represents subthreshold responsiveness. $\overline{\mathrm{R}}$ is the mean value of $R$ (as described above), and $\sigma^{2}$ is its variance. This measure of selectivity takes into account both the mean and the variance of a cell's responses. A $d^{\prime}$ value of 0.7 was used as the criterion for identifying a cell as "song-selective," that is, responding more to forward than to reversed BOS; this corresponded to a significance level of $p=0.036$ as measured by a paired $t$ test comparing $R_{\text {area }}$ or $R_{\text {FiringRate }}$ values for 20 presentations of BOS and versus reversed

For non-BOS stimuli, significance was determined with paired $t$ tests comparing baseline and stimulus responses at suprathreshold and subthreshold levels (z-scores); this detected both "excitatory" and "inhibitory" responses.

Histology. Cells were stained with neurobiotin using positive currents $(750 \mathrm{pA} ; 500 \mathrm{msec}$ at $1 \mathrm{~Hz})$. After the recording session, birds were deeply anesthetized with equithesin and transcardially perfused with $0.9 \%$ saline for $<5 \mathrm{~min}$, followed by $4 \%$ paraformaldehyde (PFA) in $25 \mathrm{~mm}$ sodium phosphate buffer for $\sim 30$ min. Brains were removed and post-fixed in $4 \%$ PFA with $30 \%$ sucrose overnight, blocked sagittally, and sectioned on a freezing microtome at $60 \mu \mathrm{m}$. Sections were processed using standard techniques (see Kittelberger and Mooney, 1999). Camera lucida drawings were made using $10 \times$ or $63 \times$ objectives, and sections were counterstained with cresyl violet to confirm LMAN's boundaries. The drug-ejection pipette position was reconstructed by the resultant track and the small space formed from the ejected bolus of drug.

\section{RESULTS}

Sharp electrode intracellular recordings were made from 299 LMAN neurons in 47 adult male zebra finches (Fig. 1B). LMAN neurons were identified by their spike shapes and responses to depolarizing currents (Fig. 2B) (Livingston and Mooney, 1997), as well as by intracellular staining. All LMAN neurons were presented with song stimuli: 236 were "song selective" (either subthreshold or suprathreshold $d^{\prime}$ values comparing forward and reversed song responses were $\geq 0.7$ ). The intrinsic and morphological properties are first described for a subset of these neurons.

\section{Song-selective LMAN neurons: morphology and intrinsic properties}

Song-selective LMAN neurons had spinous dendrites and bifurcating axons projecting ventrally to area $\mathrm{X}$ and caudally toward $\mathrm{R} A$ (Fig. $2 A$ ) and were morphologically indistinguishable from LMAN projection neurons studied in vitro (Livingston and Mooney, 1997; Boettiger and Doupe, 1998; Bottjer et al., 1998). Spontaneous and stimulus-evoked action potentials recorded from LMAN projection neurons in vivo had the gradual spike onset and sharp spike afterhyperpolarization described in vitro. Responses to injected currents were collected for a representative subset of 49 neurons, 30 of which were song selective (Fig. $2 B$; mean $V_{\text {rest }}=-72 \pm 1$ $\mathrm{mV} ; n=299$ cells). Input resistances were lower than those measured in vitro $[25 \pm 8$ vs $90 \pm 4 \mathrm{M} \Omega$ in vitro (Livingston and Mooney, 1997)], likely because of higher in vivo levels of subthreshold and suprathreshold spontaneous synaptic activity [Fig. $2 B$ vs Livingston and Mooney (1997), their Fig. 2B]. There was no correlation between input resistance and song selectivity $(r=$ $-0.14 ; p=0.59)$. Mean firing rates evoked by depolarizing currents were linear in vivo (Fig. $2 C ; 46 \pm 2 \mathrm{~Hz} / \mathrm{nA} ; r=0.998 ; p<0.02$ ), and spike rate accommodation was visible although less pronounced than in vitro (Fig. $2 D$; for $+800 \mathrm{pA}, r=-0.65$; $p<0.0001$; for $+600 \mathrm{pA}, r=-0.41 ; p<0.02)$. Interneurons were not encountered, probably because of electrode-sampling biases.

\section{Song-selective properties}

Song-selective responses typical of LMAN projection neurons are shown in Figure 2E. Individual current-clamp records (top) showing suprathreshold and subthreshold responses to forward and reversed BOS playback were used to construct PSTHs and medianfiltered trace averages (bottom). BOS playback consistently elicited subthreshold depolarizations accompanied by volleys of action potentials, whereas reversed BOS playback elicited no consistent subthreshold or suprathreshold responses. Of 299 cells tested, 183 (78\%) displayed selective responses similar to this example, whereas 52 were nonselective $\left(d^{\prime}<0.7\right)$. Another subset of LMAN projection neurons did not fire action potentials spontaneously or to BOS playback, despite displaying robust spontaneous synaptic activity $(n=64)$. However, $53(83 \%)$ of these "silent" cells still displayed subthreshold selectivity (Materials and Methods), a percentage similar to that of selective spiking neurons. As described in extracellular studies (Doupe, 1997), the temporal pattern of responsivity was similar across multiple cells within individual birds and did not vary as a function of location with the nucleus (data not shown).

\section{Responses to non-BOS stimuli}

Most cells responded only to BOS, but weaker subthreshold and/or suprathreshold responses to other stimuli were occasionally seen (Fig. 3) and included both excitatory and inhibitory responses (see Materials and Methods). Reversed-order BOS frequently elicited excitatory responses (81/236 cells), whereas inhibition was elicited in only 1 cell. Responses to reversed BOS were extremely rare (excitatory, 3/236 cells; inhibitory, 13/236 cells), and excitation consisted only of an onset response. Very few cells responded to conspecific (excitatory, 8/106; inhibitory, 4/106) or heterospecific (excitatory, 5/106; inhibitory, 5/106) songs, whereas white noise elicited more inhibitory (10/35) than excitatory (2/35) responses. The suprathreshold components of these response properties are similar to those described in extracellular studies of LMAN (Doupe, 1997).

\section{Song selectivity: local circuit contributions}

In vitro studies have shown afferents to LMAN from DLM to be excitatory, whereas inhibitory input arises locally from LMAN interneurons (Livingston and Mooney, 1997); LMAN projection neuron axon collaterals also provide excitation to other LMAN projection neurons and interneurons (Boettiger and Doupe, 1998) (Fig. $1 B$ ). Determining extrinsic versus local circuit contributions toward LMAN's selectivity can clarify whether LMAN synthesizes or refines its auditory output and whether it can gate these responses to its targets. To this end, the following experiments were performed: (1) subthreshold and suprathreshold measures of selectivity were compared to determine whether individual LMAN neurons could alter their own output, (2) tonic or transient currents were injected into the cell to detect acoustically evoked local inhibition, (3) LMAN's local inhibitory network was inactivated, and (4) the entire local LMAN network was inactivated. 


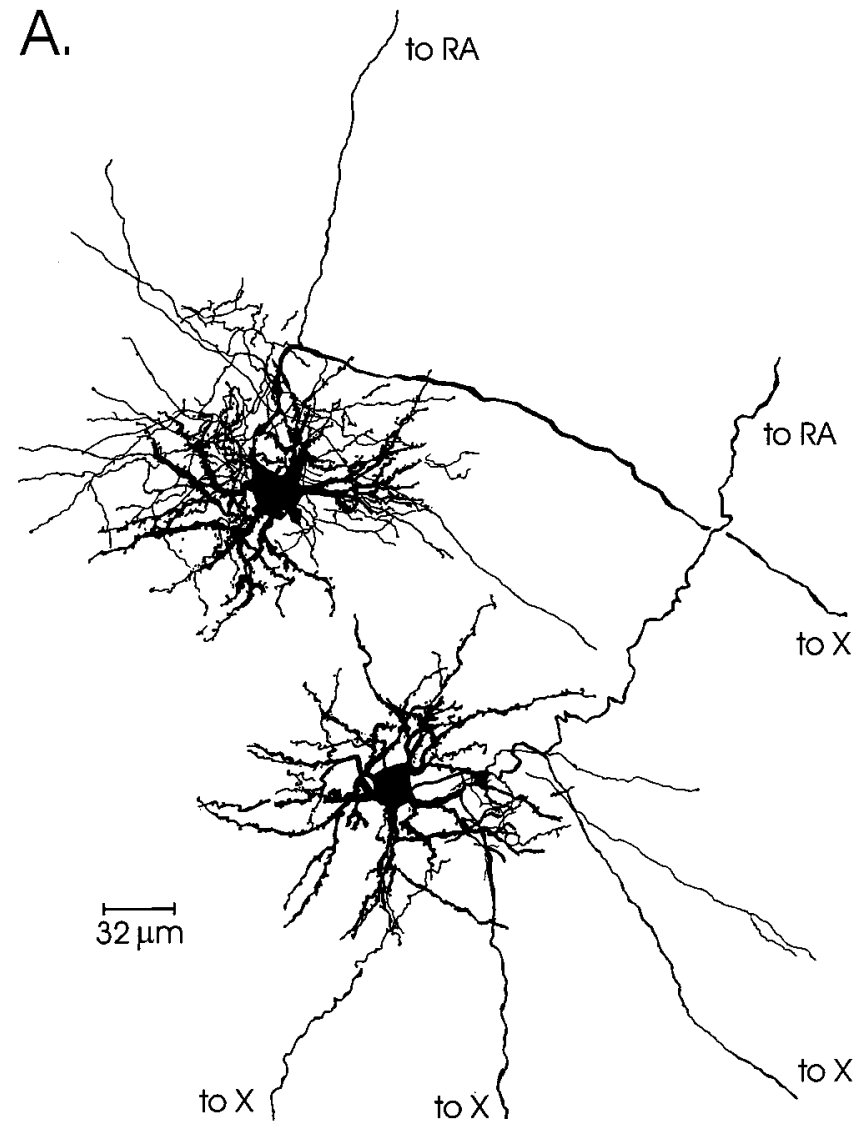

B.
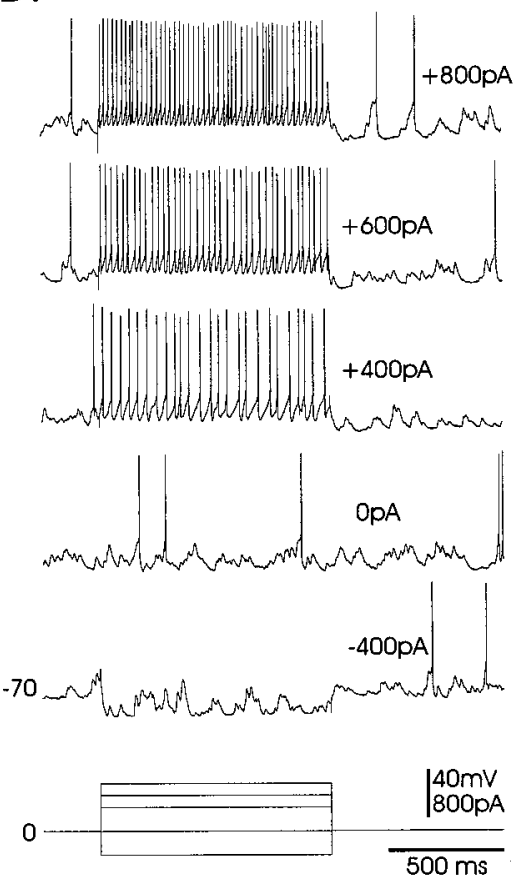

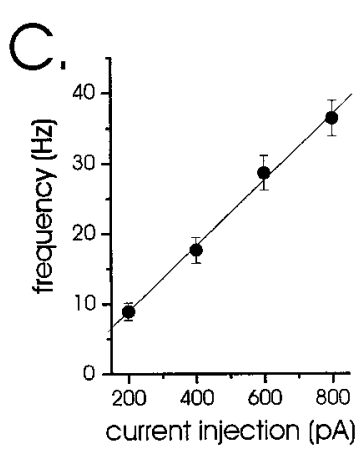

D.

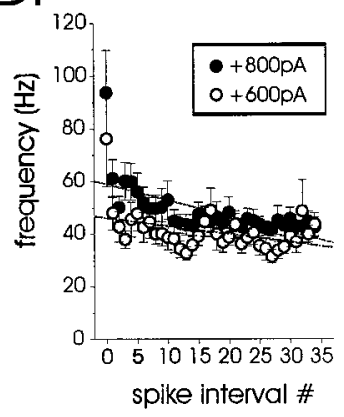

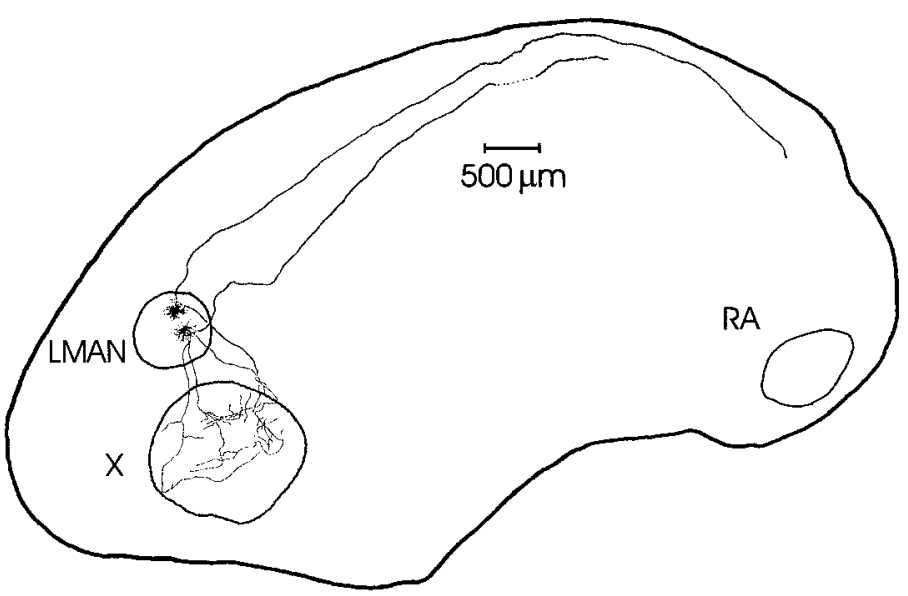

E.

$\mathrm{BOS}$

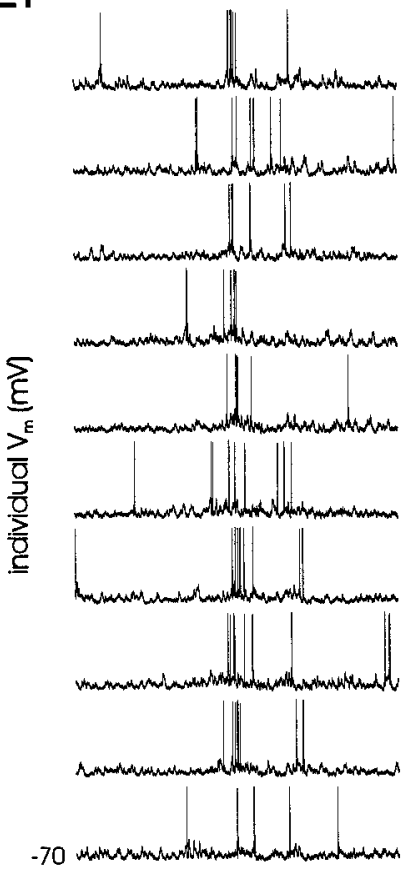

reversed $\mathrm{BOS}$
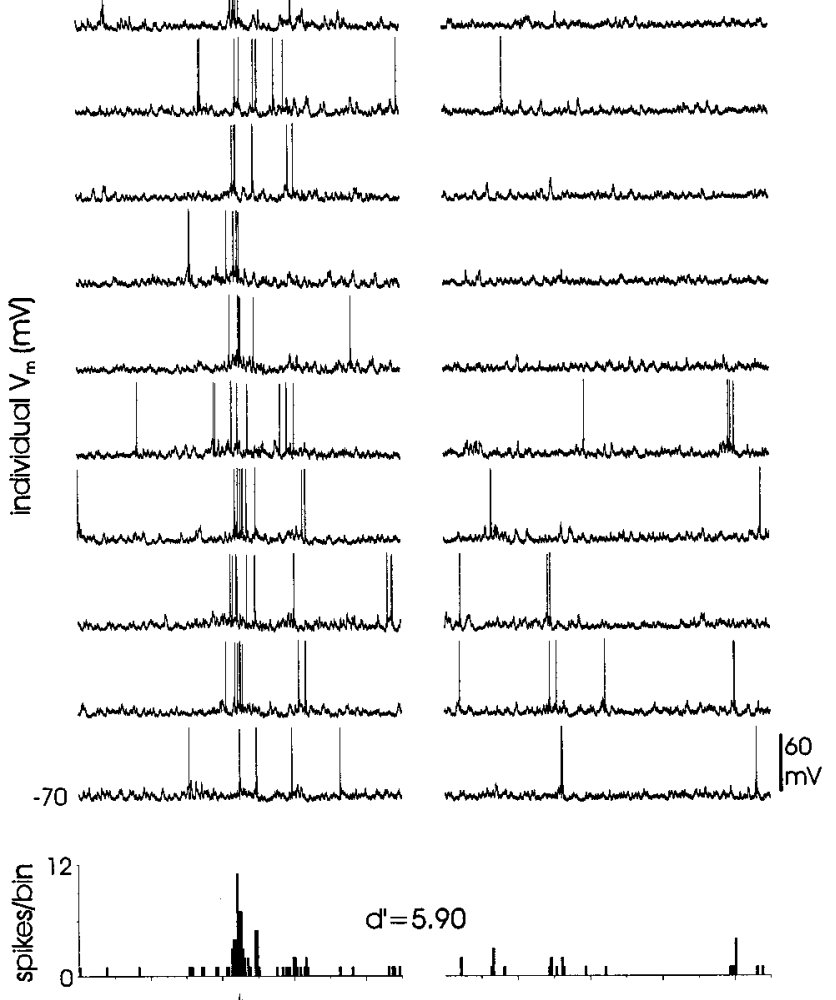

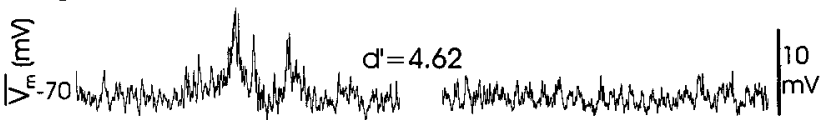
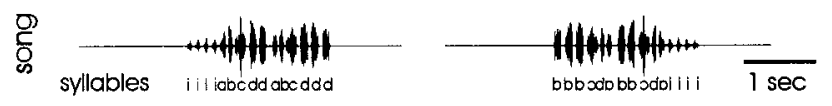

Figure 2. Morphological and physiological characterization reveals that song-selective LMAN neurons are projection neurons. $A$, Camera lucida reconstructions (objective magnification, $63 \times$, left, and $10 \times$, right ) of two song-selective LMAN neurons show that these cells are spiny projection neurons with bifurcated axons projecting toward RA and area X and local collaterals within LMAN. Because of the great distance between LMAN and RA ( $>4$ $\mathrm{mm}$ ), axons were rarely completely filled to RA. Reconstructions are in the sagittal plane; rostral is to the left; dorsal is up. B, Five traces (top) are the responses of a song-selective LMAN projection neuron to injected currents (bottom). Note the high spontaneous synaptic activity and gradual spike onset and sharp afterhyperpolarization characteristic of these neurons. $C$, The highly linear relationship of firing frequency to current injection amplitude $(n=49$ cells) is shown. $D$, Instantaneous firing frequency is plotted as a function of spike interval number, showing slight accommodation ( 1 sec pulses; +600 and $+800 \mathrm{pA}$; $n=49$ cells; dotted lines are linear fits for each current amplitude). E. Examples of a LMAN projection neuron's selective response to BOS versus reversed BOS are shown. The 10 traces at the top are raw intracellular current-clamp records of responses to repeated song stimuli [depicted as an oscillogram in the lowest trace, with syllables delineated by letters $a-d$ (i, introductory notes)]. The plot immediately below the raw traces is an action potential PSTH ( 25 msec bin width), below which is the median-filtered average $\mathrm{V}_{m}$ showing underlying subthreshold responses (see Materials and Methods). 


\section{A.}
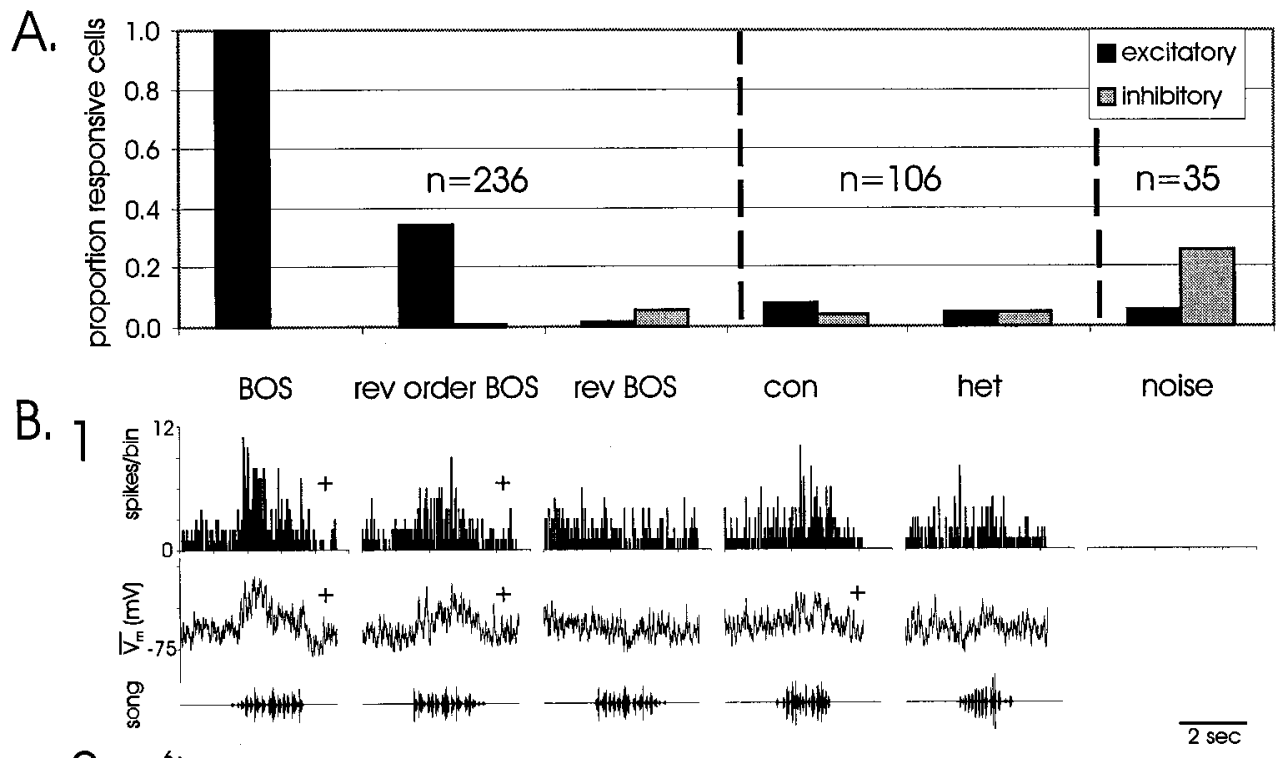

2
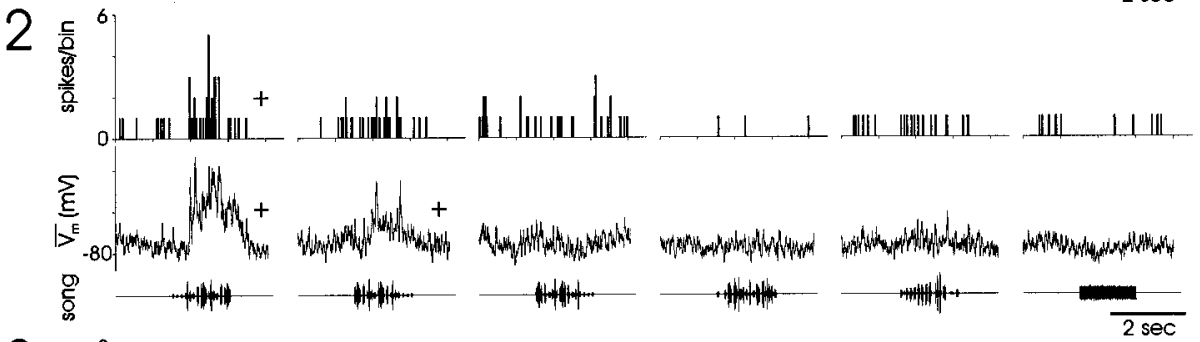

$3 \frac{1}{\frac{0}{00}}$

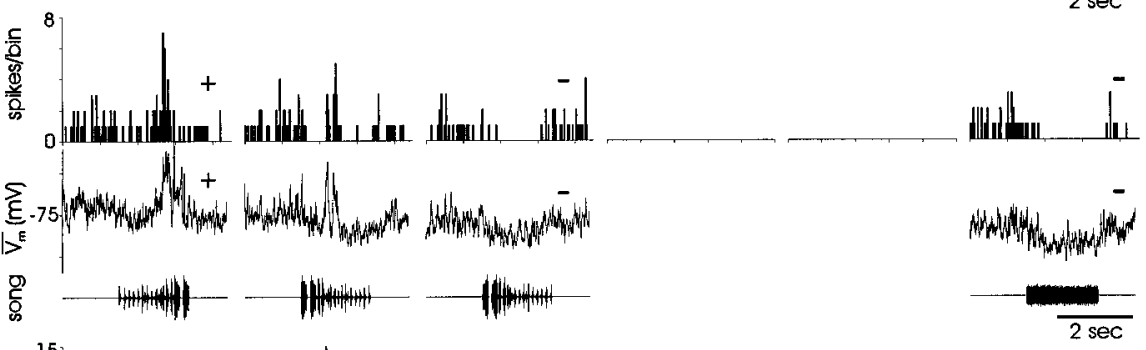

4

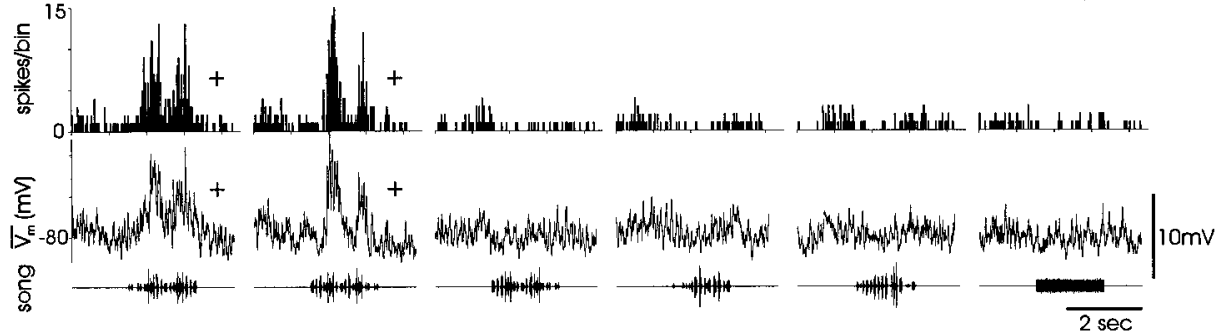

Figure 3. Song-selective LMAN neurons rarely exhibited responses to nonBOS auditory stimuli. $A$, Proportion of BOS-responsive cells $(n=236$; includes suprathreshold and/or subthreshold responsivity) that also responded to other auditory stimuli. Vertical dashed lines delineate subsets of cells that also received other stimuli. All 236 cells received reversed order BOS and reversed BOS, 106 of these cells were also tested with conspecific (con) and heterospecific (het) song, and 35 of these cells were also tested with white noise. BOS responses were always excitatory; inhibitory responses occurred to other stimuli, especially white noise. B1-B4, Examples of the BOS and non-BOS responses in cells from four birds. Significant (by paired $t$ test or $d^{\prime}$; see Materials and Methods) excitatory and inhibitory responses to auditory stimuli are indicated by + and - symbols, respectively, above individual PSTHs or median-filtered trace averages. Conventions are as described in Figure $2 E$; cells were presented with $20-30$ iterations of each stimulus.

\section{Comparison of subthreshold and suprathreshold selectivity}

The intracellular approach allows a within-cell comparison of the selectivity of synaptic inputs with suprathreshold output. In LMAN, greater suprathreshold than subthreshold selectivity could be evidence of local refinement at a single-cell level, for example, by a nonlinear thresholding mechanism (Jagadeesh et al., 1997). To compare subthreshold and suprathreshold song selectivity in single LMAN neurons, the subthreshold and suprathreshold responses of all cells $(n=299)$ were normalized using z-scores (Fig. $4 A)$. BOS responses were plotted against those from the same cell to reversed BOS, with all points to the right of the diagonal line indicating a forward song bias. The cumulative proportion of subthreshold and suprathreshold $d^{\prime}$ values of all spiking cells $(n=235)$ was plotted in Figure $4 B$. The rightward shift of suprathreshold values (firing rate) compared with subthreshold values (area) revealed more cells were selective at a suprathreshold than at a subthreshold level (Kolmogorov-Smirnov goodness-of-fit test, $p<0.0001$ ); as a population, cells were more highly selective at suprathreshold than at subthreshold levels $\left(d^{\prime}\right.$ FiringRate $=1.41 \pm 0.08 ; d^{\prime}$ area $=1.13 \pm 0.09$; paired $t$ test: $p<0.0001$; statistic computed for all data points shown in Fig. 4E).

One impression was that certain cells displayed large $d^{\prime}$ values at a suprathreshold level, with minimal subthreshold change, presumably because their resting membrane potentials were closer to spike threshold, resulting in small-amplitude EPSPs. Indeed, plots of firing rate or area versus resting membrane potential revealed a slight negative correlation between subthreshold selectivity and $\mathrm{V}_{\text {rest }}$ (Fig. $4 C, D ; r=-0.13 ; p=0.027$ ), with no significant correlation between suprathreshold selectivity and $\mathrm{V}_{\text {rest }}(r=0.05 ; p=$ 0.47 ). To clarify further that differences in subthreshold versus suprathreshold selectivity were caused by $V_{\text {rest }}$ and not refinement per se, cells were divided into two subpopulations based on $\mathrm{V}_{\text {rest }}$ [positive vs negative of $-74.5 \mathrm{mV}$ to create subpopulations of approximately equivalent sizes; this value is near the mean $\mathrm{V}_{\text {rest }}$ for the population $(-72 \mathrm{mV})]$, and $d^{\prime}$ values for area and firing rate were plotted against one another for each cell (Fig. $4 E$ ). Only cells 

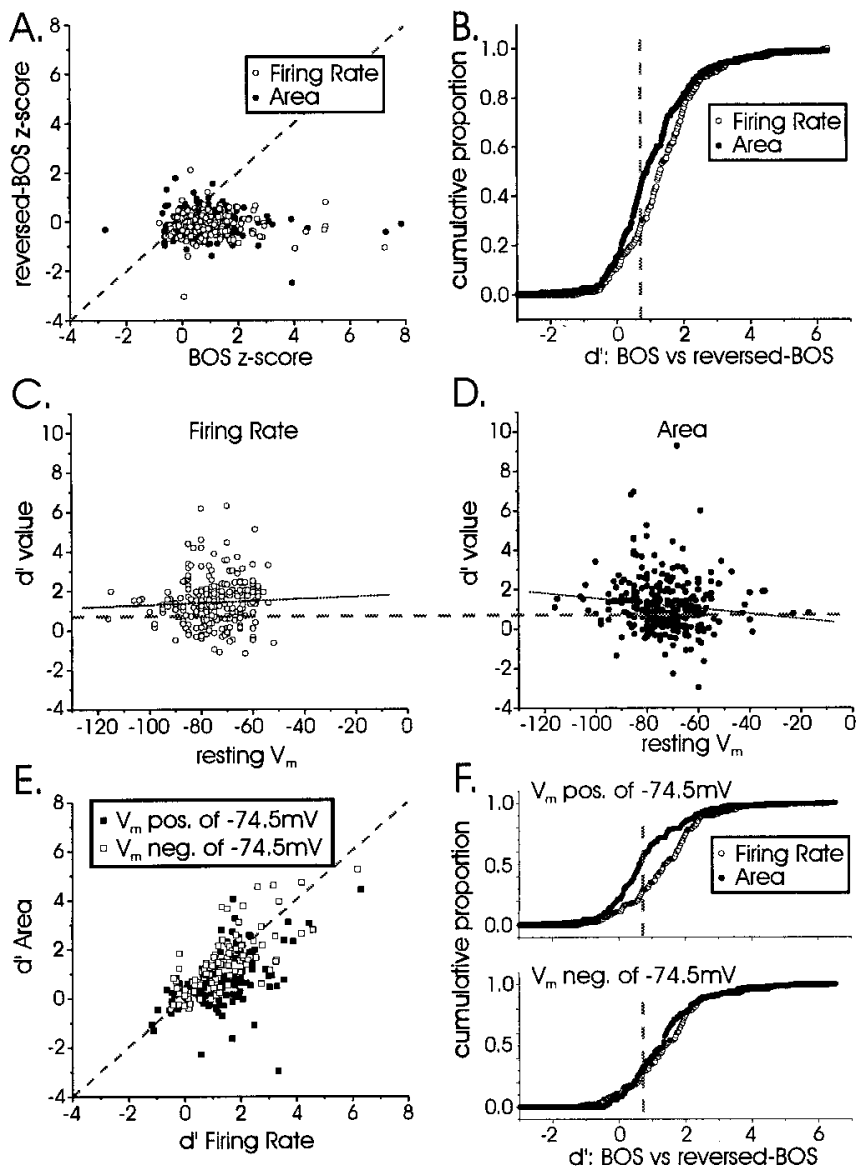

G
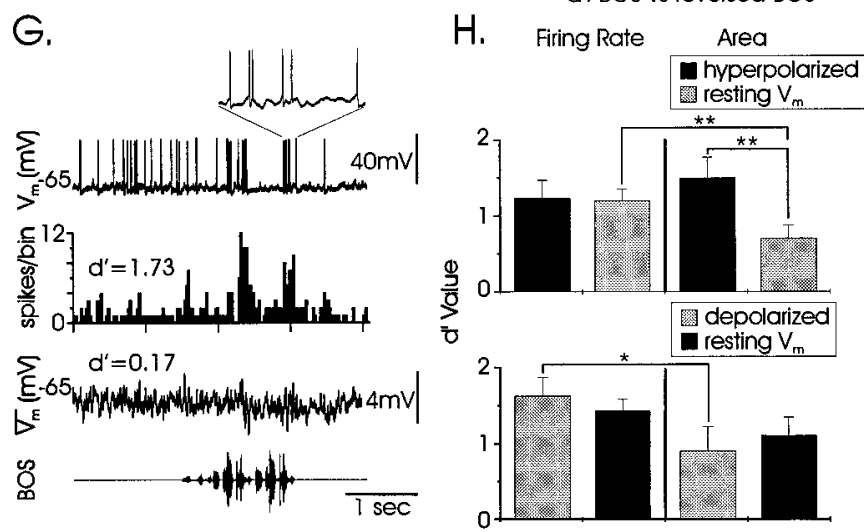

Figure 4. A population analysis of LMAN projection neurons reveals equivalent song selectivity at subthreshold and suprathreshold levels. $A$, Normalized responses (z-scores) to BOS are plotted against those to reversed BOS, for both suprathreshold (firing rate) and subthreshold (area) activity $(n=299$ cells). The points to the right of the diagonal line are cells with a bias for forward song. $B$, The discrepancy between subthreshold and suprathreshold selectivity for all spiking cells $(n=235)$ is plotted as a cumulative proportion of $d^{\prime}$ values. The dashed vertical line indicates the criterion for significant selectivity $\left(d^{\prime}=0.7\right)$. $C, D$, Scatter plots of suprathreshold and subthreshold $d^{\prime}$ values with resting $\mathrm{V}_{m}$ show a significant negative correlation for area $(r=-0.13 ; p=0.027)$ but no significant correlation for firing rate $(r=0.05 ; p=0.47) . E$, Suprathreshold versus subthreshold selectivity for $d^{\prime}$ values comparing BOS and reversed BOS, for all cells with spiking activity $(n=235)$, is shown. Positive-resting cells (black; $n=125)$ are less selective at subthreshold than at suprathreshold levels, whereas negative-resting cells (white; $n=110$ ) are equally selective at subthreshold and suprathreshold levels (see Discussion). The diagonal line represents equal subthreshold and suprathreshold selectivity. $F$, The discrepancy between subthreshold and suprathreshold selectivity exists only for positive-resting (top) and not negative-resting (bottom) cells; data from $E$ are plotted as cumulative proportions of subthreshold and suprathreshold $d^{\prime}$ values. $G$, An example of a cell that exhibited suprathreshold but not subthreshold selectivity is shown; contrast with the cell depicted in Figure $2 E$. The top trace and inset show a response to one presentation of BOS; note how the spikes arise from the baseline with minimal subthreshold EPSPs. Conventions are as described in in the more positive group (mean $\mathrm{V}_{m}=-64.9 \pm 0.6$, significantly different from the population $\mathrm{V}_{m}, p<0.0001$, paired $t$ test) showed a significant discrepancy between subthreshold and suprathreshold $d^{\prime}$ measures $\left(d_{\text {FiringRate }}^{\prime}=1.43 \pm 0.10 ; d_{\text {area }}^{\prime}=0.82 \pm 0.12 ; p<\right.$ $0.0001 ; n=125)$. In contrast, negative-resting cells (mean $\mathrm{V}_{m}=$ $-82.0 \pm 0.7$, significantly different from the population $\mathrm{V}_{m}, p<$ 0.0001 , paired $t$ test) were equally selective by both measures $\left(d_{\text {FiringRate }}^{\prime}=1.32 \pm 0.11 ; d_{\text {area }}^{\prime}=1.47 \pm 0.12 ; p=0.34 ; n=110\right)$. This discrepancy is clearly visible when the cumulative proportions of subthreshold and suprathreshold $d^{\prime}$ values are plotted for the two subpopulations (Fig. $4 F$ ). This is consistent with the idea that positive-resting cells have artifactually reduced $d^{\prime}$ areal values because song-evoked EPSPs have a decreased driving force [i.e., they are closer to the reversal potential for glutamatergic currents as well as to spike threshold (see Discussion)]. An example of such a positive-resting cell is depicted in Figure $4 G\left(\mathrm{~V}_{\text {rest }}=-66 \mathrm{mV}\right)$; compare this cell with the more negative-resting cell depicted in Figure $2 E\left(\mathrm{~V}_{\text {rest }}=-72 \mathrm{mV}\right)$, which has a spike threshold further from rest and thus larger amplitude EPSPs. These results suggest that subthreshold inputs onto LMAN projection neurons, intrinsic or extrinsic to LMAN, are as selective as the output of these cells when probed with forward and reversed BOS.

To test directly whether changing a single cell's membrane potential could influence its selectivity, tonic hyperpolarizing or depolarizing currents were injected through the recording electrode. Hyperpolarization $\left(\mathrm{V}_{\text {rest }}=-71.4 \pm 1.5 \mathrm{mV} ; \mathrm{V}_{\text {hyperpol }}=\right.$ $-88.4 \pm 2.0 \mathrm{mV} ; p<0.0001 ; n=26)$ did not alter suprathreshold selectivity, although it did significantly increase subthreshold selectivity (Fig. 4H, top, within-quadrant comparisons; $d^{\prime}$ area : rest, $0.71 \pm 0.16$; hyperpolarized, $1.50 \pm 0.27 ; p<0.02 ; d^{\prime}{ }_{\text {FiringRate }}$ : rest, $1.20 \pm 0.15$; hyperpolarized, $1.24 \pm 0.23 ; p=0.87$ ). This effect on subthreshold selectivity is likely caused by an increased driving force on song-evoked EPSPs at more negative resting potentials. Consistent with this idea and with the mismatch between subthreshold and suprathreshold measures of selectivity described above, $d^{\prime}$ measures of subthreshold versus suprathreshold selectivity only differed for these cells in the more positive state (Fig. $4 H$, top; paired $t$ test for black bars, $p=0.93$; paired $t$ test for gray bars, $p=0.002)$. Similarly, paired analyses of cells that were tonically depolarized $\left(\mathrm{V}_{\text {rest }}=-82.0 \pm 2.3 \mathrm{mV} ; \mathrm{V}_{\text {depol }}=-62.9 \pm 5.3 \mathrm{mV}\right.$; $p<0.0006 ; n=12$ ) revealed that $d^{\prime}$ measures of subthreshold versus suprathreshold selectivity also only differed for these cells in the more positive state (Fig. $4 \mathrm{H}$, bottom; paired $t$ test for gray bars, $p=0.03$; paired $t$ test for black bars, $p=0.05)$. Finally, there was no effect of depolarization on either subthreshold or suprathreshold selectivity (Fig. 4H, bottom, within-quadrant comparisons; $d^{\prime}{ }_{\text {area }}$ : rest, $1.11 \pm 0.24$; depolarized, $0.90 \pm 0.32 ; p=0.55$; $d_{\text {FiringRate }}^{\prime}$ : rest, $1.43 \pm 0.15$; depolarized, $1.63 \pm 0.24 ; p=0.37$ ). (Although the trend was in the right direction, the lack of a significant effect on subthreshold selectivity after depolarization was unexpected. See below for more extreme depolarization effects on selectivity.) Thus, although membrane potential could affect subthreshold measures of selectivity, altering $\mathrm{V}_{m}$ at a single-cell level did not influence output, as measured by firing-rate selectivity.

\section{Current injection to detect local inhibition}

In the song nucleus HVc and the mammalian visual cortex, selectivity involves pronounced inhibition and excitation (Ferster, 1986; Lewicki, 1996; Mooney, 2000). To test whether inhibition contributes to song selectivity in LMAN, the membrane potential of

Figure $2 E . H$, Hyperpolarization (top; $n=26$ ) and depolarization (bottom; $n=12$ ) of single cells with tonic current did not alter their firing-rate selectivity. Consistent with the discrepancy shown in $F$, a mismatch between subthreshold and suprathreshold selectivity arose when cells were more positive resting ( gray bars, top and bottom). Subthreshold selectivity (area) increased when cells were more negative resting, although this was only significant for hyperpolarized cells. $d^{\prime}$ values from cells with negativeresting potentials are shown in black, and those with positive-resting potentials are shown in gray (paired $t$ tests, ${ }^{*} p<0.05 ; * * p<0.01$ ). 
song-selective cells was varied to distinguish IPSPs from EPSPs. The membrane potential of cells dialyzed with cesium and the sodium channel blocker QX-314 could be shifted to very depolarized values via current injection $\left(\mathrm{V}_{\text {rest }}=-57.1 \pm 3.5 \mathrm{mV} ; \mathrm{V}_{\text {depol }}\right.$ $=-4.5 \pm 4.6 \mathrm{mV} ; p<0.0001 ; \Delta \mathrm{V}_{m}=+52 \mathrm{mV} ; n=8$ cells $)$, rendering spontaneous IPSPs hyperpolarizing (Fig. 5A, arrows) and distinct from EPSPs, which remained depolarizing. In this tonically depolarized state, selectivity across these cells (although not for this example) was significantly reduced but still robust $\left(d^{\prime}{ }_{\text {rest }}\right.$ $\left.=1.57 \pm 0.22 ; d^{\prime}{ }_{\text {depol }}=1.05 \pm 0.16 ; p=0.04\right)$. This is consistent with the population data in which more positive cells exhibited reduced subthreshold selectivity. Importantly, no component of the subthreshold response to forward or reversed BOS was hyperpolarizing (Fig. $5 A$ ). This suggests that the song-evoked synaptic drive to LMAN does not involve appreciable local GABAergic inhibition.

Although song-evoked inhibition was not detected, LMAN has been distinguished from earlier stages of the AFP (i.e., area X) by firing-rate suppression to noise stimuli (Doupe, 1997). The noiseevoked inhibitory responses seen here included membrane hyperpolarization in addition to firing-rate suppression (e.g., Fig. 3B3), which could reflect either local inhibition or reduced tonic excitatory drive, processes that should involve large increases or small decreases, respectively, in membrane conductance (see Discussion). To distinguish between these two possibilities, we assessed input resistance by monitoring responses to noise versus silence while injecting trains of short hyperpolarizing currents $[10 \mathrm{msec}$ duration; -500 pA; $\sim 20 \mathrm{~Hz}$ (cf. Jan et al., 1980)]. Input resistance, as measured by current-induced voltage deflection, increased slightly but not significantly during noise presentation (Fig. $5 B$; $\Delta \mathrm{V}=-14.88 \pm 3.39 \mathrm{mV} ; \Delta \mathrm{V}_{m \text { noise }}=-15.08 \pm 3.31 \mathrm{mV}$ paired $t$ test, $p=0.43 ; n=9$ cells in 5 birds), suggesting that hyperpolarization and reduced firing rate reflect reduced tonic excitatory drive. Finally, comparisons of subthreshold versus suprathreshold response measures (z-scores) to white noise showed equivalent responsiveness (Fig. $5 C$; paired $t$ test, $p=0.45 ; n=41$ cells), implying that nonlinear mechanisms at the single-cell level are unlikely to underlie hyperpolarizing responses to white noise.

\section{Inactivation of $L M A N^{\prime}$ s local inhibitory network}

The apparent lack of stimulus-evoked inhibition in LMAN was curious, because of LMAN's robust inhibitory circuitry (Livingston and Mooney, 1997; Boettiger and Doupe, 1998; Bottjer et al., 1998). Thus, the local inhibitory network's role in song selectivity was directly examined by removing local inhibition via pressure ejection of bicuculline methiodide (BMI) onto the nucleus. This caused LMAN neurons to burst rhythmically (Fig. $6 \mathrm{~A}$, middle) and also depolarized them (Fig. $6 C ; \mathrm{V}_{\text {rest }} \mathrm{BMI}=-64.5 \pm 4.2 \mathrm{mV}$; washout $=-74.6 \pm 4.2 \mathrm{mV}$; paired $t$ test, $p<0.01 ; n=10)$. Over 1 to several hours, the bursting dissipated, suggesting BMI washout (Fig. 6A, right). The song selectivity of $10 \mathrm{LMAN}$ neurons (in six birds), impaled immediately after BMI application when LMAN was strongly disinhibited, was measured during and after recovery from BMI (seven cells were recorded with QX-314-containing electrodes to minimize action potential contamination of subthreshold responses). In 7 of 10 cells, selectivity was absent during disinhibition but emerged during washout (Fig. $6 B, C$; in $2 / 7$ cells recorded without QX-314, both firing-rate and subthreshold selectivity emerged only after washout). Furthermore, the 3 other LMAN neurons that were selective in BMI were dramatically more selective after washout; across all cells, selectivity significantly increased after washout (Fig. $6 C ; d^{\prime}$ area $\mathrm{BMI}=0.46 \pm 0.27$; washout $=1.87 \pm 0.37$; paired $t$ test, $p<0.0001)$. Although subthreshold $d^{\prime}$ increases may be caused by more negative resting potentials after washout, firing-rate selectivity, which is not sensitive to resting potential (see above), also increased after washout (Fig. $6 C$, black arrows; $d^{\prime}{ }_{\mathrm{BMI}}=0.36 \pm 0.36 \mathrm{mV} ; d^{\prime}{ }_{\text {washout }}=1.79 \pm$ $0.58 \mathrm{mV}$; paired $t$ test, $p=0.03 ; n=3$ ). These results indicate that the local inhibitory network is needed to maintain selectivity in LMAN.
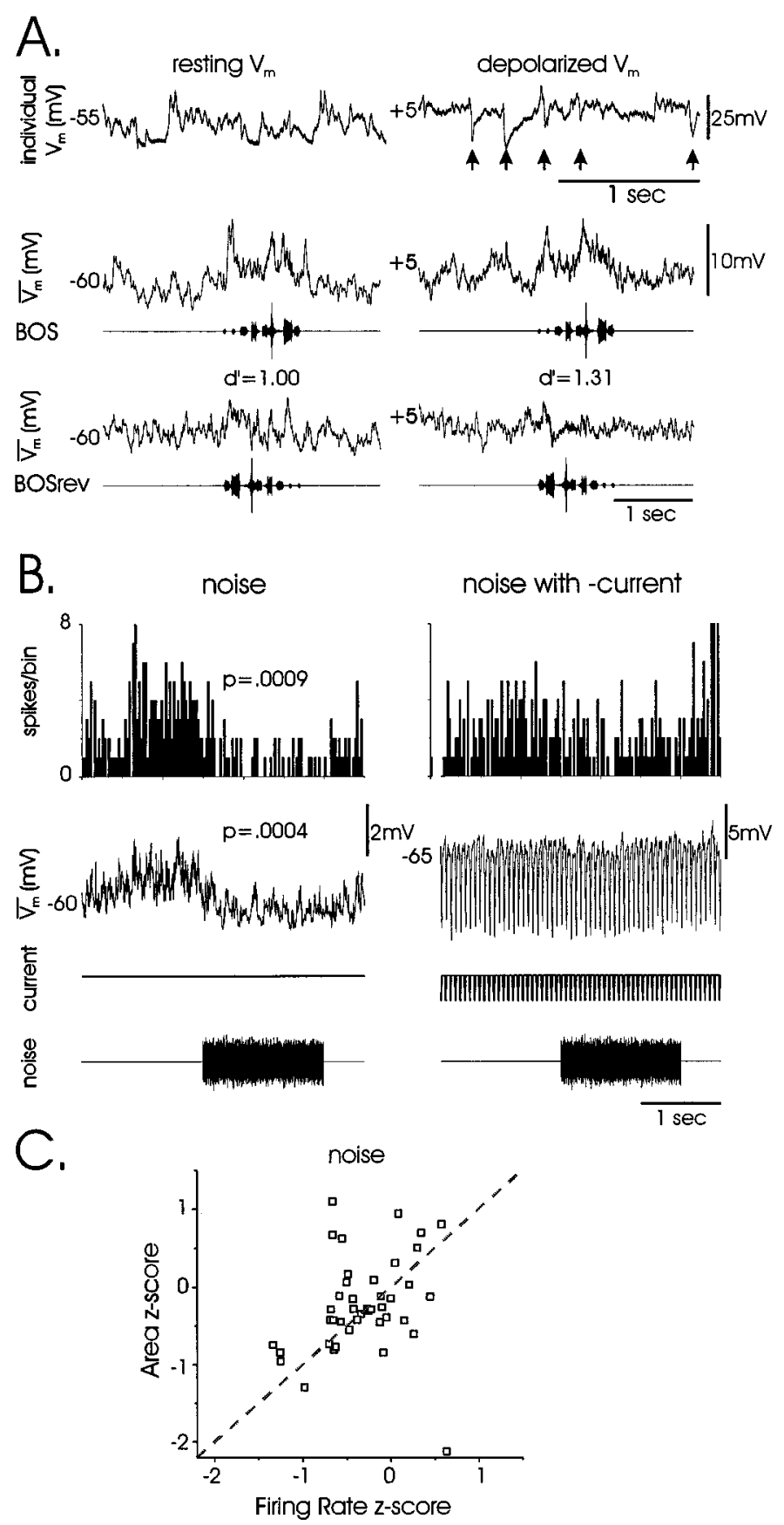

Figure 5. Absence of song and noise-evoked local inhibition. $A$, Inhibitory events are not evoked by either forward or reversed BOS playback. The cell is shown at resting membrane potential (left $)$ and with tonic depolarizing current injection (right; recorded with a CsAc/QX-314 electrode to facilitate depolarization). Top Row, Traces show spontaneous activity including inhibitory events (arrows), visible when the cell is strongly depolarized $\left(\mathrm{V}_{\text {rest }}=+5 \mathrm{mV}\right)$ by tonic current. Middle, Bottom Rows, Traces show that inhibitory events are not evoked during presentation of either forward or reversed BOS [median-filtered responses at rest (left) and depolarized (right); song oscillograms (BOS, middle; BOS reverse, bottom) below each trace]. For this cell, $d^{\prime}$ slightly increased after depolarization, although $d^{\prime}$ for other cells and overall decreased significantly (see Results). Conventions in $A$ and $B$ are as described in Figure $2 E$. $B$, Noise-evoked firing-rate suppression and membrane hyperpolarization were not accompanied by conductance changes, as measured by trains of hyperpolarizing current pulses $(10 \mathrm{msec} ;-500 \mathrm{pA} ; \sim 20 \mathrm{~Hz})$. This is consistent with a noise-evoked reduction in tonic excitation rather than an increase in local inhibition. $C$, Suprathreshold and subthreshold responses (z-score firing rate vs area) to white noise are equivalent, suggesting the absence of thresholding effects to noise stimuli at a single-cell level (see Results). 


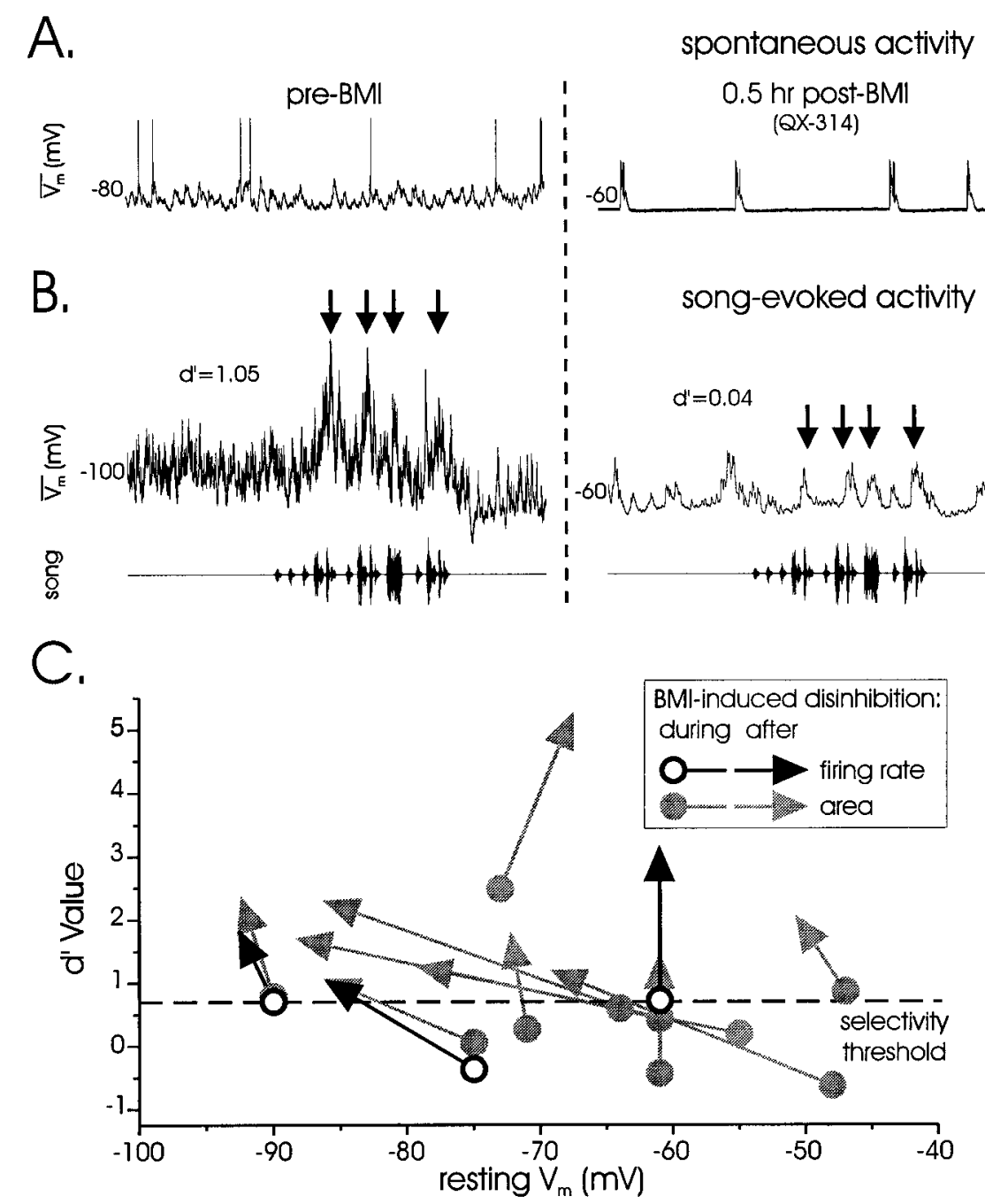

Figure 6. The local inhibitory network within LMAN is needed to maintain a high degree of song selectivity. $A$, Spontaneous activity was recorded sequentially in two cells from a single bird, one before BMI application ( pre) and the other afterward ( post), first when BMI-induced bursting activity was evident $(0.5 \mathrm{hr})$ and then after washout when bursting had ceased ( $2 \mathrm{hr}$; QX-314 was used in the second recording). This comparison across two cells is possible because all cells within a single bird exhibited similar temporal response profiles to song. $B$, Although significant responses to BOS were present only before BMI application and after washout, peaks in the averaged traces during BMI-induced disinhibition often coincided with song-induced peaks in the control condition (arrows; cells and times as described in $A) . C, d^{\prime}$ measures of selectivity during and after BMI treatment are plotted as a function of $\mathrm{V}_{\text {rest }}(n=10$ cells; 3 spiking cells indicated with black and gray arrows; 7 QX-314 cells indicated with gray arrows only).

\section{Inactivation of LMAN's entire local network}

In several BMI-treated cells that were statistically nonselective, responses often matched the temporal profile of selective responses displayed after washout (Fig. 6B, arrows). This could reflect that highly selective extrinsic afferents to LMAN are masked by the recurrent excitation exhibited by the disinhibited circuit. To measure the selectivity of these extrinsic inputs directly, the entire local circuit was inactivated with GABA while intracellularly recording from LMAN projection neurons during song playback. GABAinduced electrophysiological inactivation is assumed to reflect the shunting of positive currents via activated $\mathrm{Cl}^{-}$conductances, thus preventing cells from spiking. Inhibitory interneurons were presumed to be inactivated in this way by GABA application, because they are likely to contain GABA receptors; any remaining activity would in any case be ineffective, because their postsynaptic GABAergic actions on LMAN projection neurons would be occluded by excess GABA. Inactivation of LMAN projection neurons was confirmed by passing large positive currents $(+1 \mathrm{nA})$ through the recording electrode and noting that the cell failed to fire action potentials (Fig. 7B, middle; compare PSTHs in GABA with those before and after treatment; see Fig. $2 B$ for control responses to similar currents). The spatial extent of inactivation was assessed by intracellularly staining GABA-silenced cells in disparate locations across LMAN while ejecting fixed amounts of GABA from a single location (see Fig. 7A). These measurements indicated that the entire extent of LMAN was inactivated during GABA application.

Before, during, and after GABA application, forward and reversed BOS were delivered to assess selectivity, and positive currents were applied to monitor inactivation and recovery. As GABA took effect, cells hyperpolarized slightly $\left(\mathrm{V}_{\mathrm{GABA}},-77.8 \pm 1.8 \mathrm{mV}\right.$; $\mathrm{V}_{\text {wash }},-73.7 \pm 1.7 \mathrm{mV}$; paired $t$ test, $p<0.005$ ), spontaneous PSP amplitudes decreased markedly, and the impaled cell ceased to spike when injected with positive currents. All 13 LMAN neurons tested were song selective after this inactivating treatment (of the three cells measured before GABA application, all were selective; $d_{\text {pre-GABA }}^{\prime}=2.82 \pm 1.31$ ), and all became refractory to spiking during GABA application. In each case, however, BOS playback evoked very small $(<2 \mathrm{mV})$ depolarizations in the absence of local circuit activity (Fig. 7B, middle), the time course of which resembled BOS-evoked depolarizations seen in control conditions (Fig. $7 C$, left, middle). In 12 of the 13 cells, selective responses were 


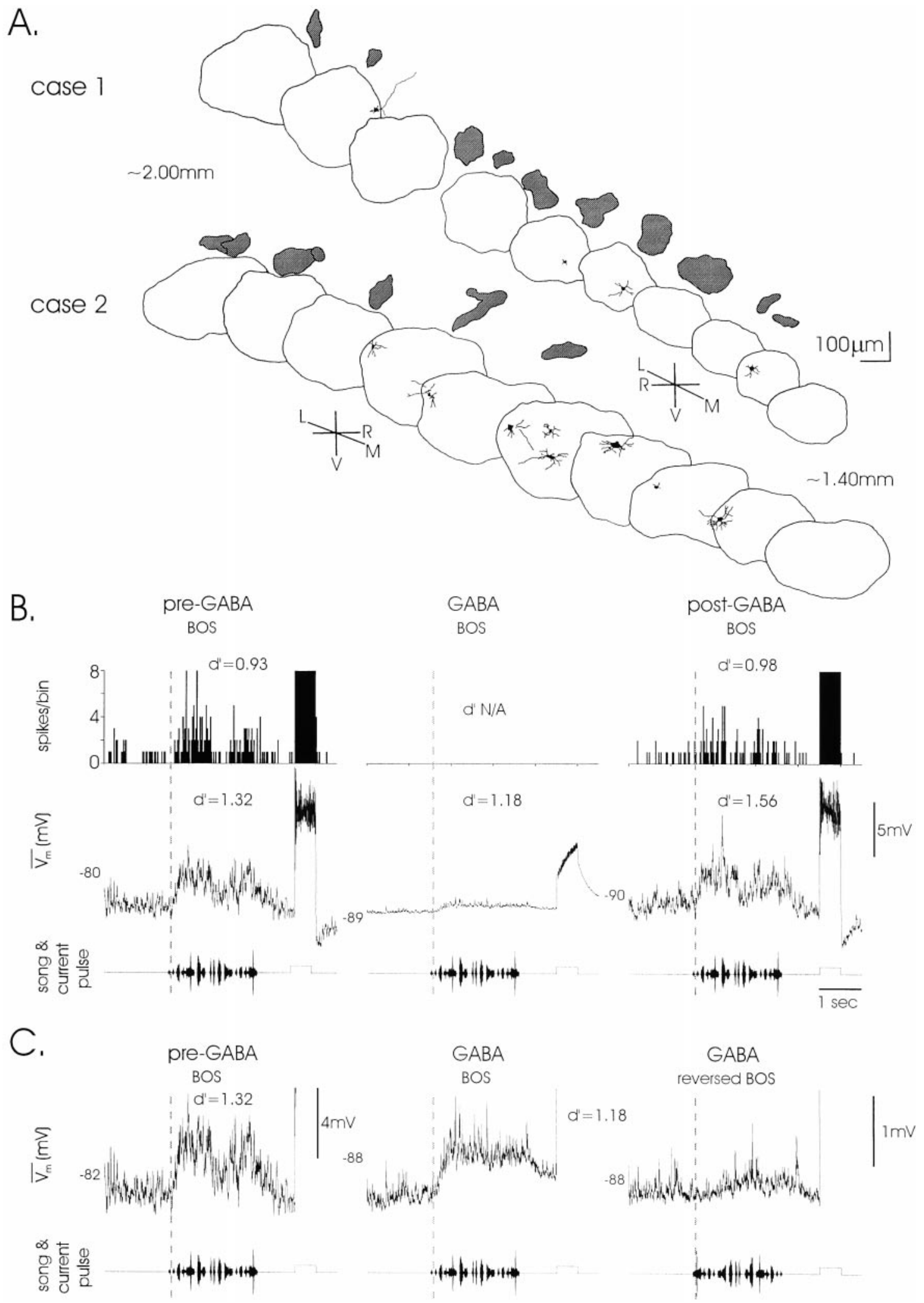

Figure 7. Silencing local LMAN circuitry with GABA reveals persistently song-selective extrinsic inputs. $A$, GABA treatment inactivated the entire extent of LMAN, as indicated by examples from two birds (cases 1,2). All stained LMAN neurons shown were silenced by GABA application (dark spots above LMAN mark the drug bolus from the stationary pipette). B, LMAN neurons maintained selective subthreshold responses when the local circuit was inactivated with GABA. Selective subthreshold and suprathreshold responses to BOS versus reversed BOS (data not shown, but see $C$ ) are visible preand post-GABA. Although no spontaneous, song- or DC-evoked spiking occurred during GABA application, the same cell maintained selective subthreshold responses despite a greatly reduced amplitude of synaptic activity. Positive currents $(+1 \mathrm{nA} ; 0.5 \mathrm{sec})$ injected after each playback evoked action potentials before and after GABA treatment but only small depolarizations in GABA. $d^{\prime}$ values compare BOS (depicted) with reversed BOS (data not shown) responses. The bottom row depicts the timing of song playback and current injection. $C$, Normalized song-evoked responses from $B$ reveal similar shapes and time courses of BOS responses with and without local circuit activity. The two traces on the right contrast forward and reversed BOS responses in GABA $\left(d^{\prime}=1.18\right)$. The vertical scale bar on the right $(1 \mathrm{mV})$ applies to middle and right panels. Vertical dotted lines in $B$ and $C$ mark the onset of song-evoked response from the leftmost trace (pre-GABA). $L$, Lateral; $M$, medial; $N / A$, not available; $R$, rostral; $V$, ventral. 
maintained but reduced in the absence of local circuit activity (Fig. $7 C$, compare middle, right; $d_{\mathrm{GABA}}^{\prime}=1.16 \pm 0.16 ; d_{\text {washout }}^{\prime}=$ $1.91 \pm 0.31$; paired $\mathrm{t}, p<0.05)$. These results indicate that extrinsic afferents to LMAN are highly selective for forward over reverse song but may be amplified by local LMAN circuitry.

\section{DISCUSSION}

The present study shows that the LMAN neurons that directly innervate vocal premotor areas (Mooney, 1992; Yu and Margoliash, 1996) are highly song selective and thus are positioned to provide auditory information to vocal control circuits (i.e., the VMP). Direct comparisons of subthreshold and suprathreshold selectivity indicate that selectivity is not augmented by individual LMAN neurons. Along with an absence of song- or noise-evoked local inhibition, these results suggest that LMAN is not a site of auditory refinement. Instead, local inactivation experiments reveal that the extrinsic afferents are already highly tuned to the bird's own song but that the local circuit is capable of masking persistently selective extrinsic inputs and thus could alter the relay of auditory information to the VMP.

Intracellular staining and histological reconstruction reveal that song-selective LMAN neurons are projection neurons with spinous dendrites and bifurcated axons that innervate both area X and RA, as well as ramifying locally. LMAN projection neurons recorded in vivo differed slightly from their in vitro counterparts (Livingston and Mooney, 1997) in exhibiting a lower input resistance, likely because of higher spontaneous synaptic activity of the intact brain. Additionally, spike rate accommodation was not as pronounced over long durations in vivo $(\sim 1 \mathrm{sec})$, although it was still dramatic over the first several spike intervals, suggesting that it could influence the cell's firing rate in response to synaptic potentials that are typically of short duration. Establishing that LMAN projection neurons are song selective links the detailed in vitro characterization of these neurons' synaptic connectivity with the extensive in vivo extracellular characterization of song selectivity in LMAN (Doupe, 1997). Therefore, song-selective LMAN neurons receive exclusively excitatory glutamatergic input from the thalamic nucleus DLM, as well as glutamatergic inputs from other LMAN projection neurons and GABAergic inputs from LMAN interneurons (Vates and Nottebohm, 1995; Livingston and Mooney, 1997; Boettiger and Doupe, 1998). Ultimately, song-selective LMAN neurons are anatomically positioned to influence their own response properties, as well as to provide auditory feedback to premotor areas used in singing.

Indeed LMAN must be intact to permit the changes in adult song structure that normally occur when the tracheosyringeal nerve is sectioned or the bird is deafened, two perturbations that create a mismatch between intended vocal output and auditory feedback (Williams and Mehta, 1999; Brainard and Doupe, 2000). Such an error correction role for LMAN also has been invoked to explain the severely disruptive effects of LMAN lesions on song development (cf. Bottjer et al., 1984; Mooney, 1992; but see Kittelberger and Mooney, 1999). Because of its putative role in providing auditory feedback for song learning and adult song maintenance, LMAN has been the site of intensive extracellular electrophysiological analysis of song-evoked auditory responses (Doupe and Konishi, 1991; Doupe, 1997; Solis and Doupe, 1997). These previous studies have not determined whether LMAN is a site at which song-selective properties are synthesized anew, is the locus of further refinement of less-selective afferents, or is simply a relay for already highly refined and song-selective input.

Arguing against LMAN as a site where song selectivity arises, anatomical studies (Vates et al., 1996) suggested that LMAN's primary and perhaps exclusive source of auditory input arises indirectly from HVc, via area X and DLM, and extracellularrecordings showed that certain DLM neurons are song selective (Doupe and Konishi, 1991). However, the lack of an extensive analysis of DLM song selectivity left unclear the detailed selectivity of LMAN's extrinsic inputs. In this study, local inactivation using GABA reveals that extrinsic inputs onto LMAN neurons are highly selective for BOS, excluding LMAN as a site of de novo synthesis of song selectivity and showing that neither local collateral activity nor feedback to area $\mathrm{X}$ are needed to sustain songevoked responses in LMAN. Although selectivity persisted in GABA, it did decrease significantly, suggesting that LMAN's local circuitry may amplify the existing song selectivity from extrinsic sources. However, the diminution of song-evoked responses remaining in GABA $(<1 \mathrm{mV})$ to a level close to the limitations in the resolution of the recording technique make it difficult to assign the selectivity decrease unequivocally to the removal of the local circuit.

Previous studies have suggested an auditory refinement role for LMAN (Maekawa and Uno, 1996; Doupe, 1997). Although area X and LMAN both respond to BOS, area $\mathrm{X}$ is more responsive to tone and noise bursts than is LMAN and, unlike LMAN, is never inhibited by such stimuli (Doupe, 1997). This difference might arise from refinement in LMAN, but refinement may also occur earlier in the AFP. The present experiments reveal slightly higher $d^{\prime}$ measures of selectivity for firing rate than for area in single LMAN neurons, but this mismatch is most readily explained by the decreased driving force on underlying evoked synaptic potentials in those cells with resting potentials close to the glutamate reversal potential. This view is further supported by the absence of such a mismatch in cells with more negative $V_{\text {rest }}$ and by the lack of changes in firing-rate selectivity induced by altering $\mathrm{V}_{m}$. These data indicate that refinement does not occur at the level of single LMAN neurons. This is in contrast with some neurons in HVc, which show a mismatch between subthreshold and suprathreshold selectivity and in which $\mathrm{V}_{m}$ manipulations reveal a refinement of suprathreshold selectivity (Mooney, 2000).

Further evidence against a refinement role for LMAN is the absence of any detectable inhibitory component in responses to either forward or reversed BOS, as might be expected if the local inhibitory network further sculpted BOS responses or suppressed responses to reversed BOS. This lack of inhibition is surprising, because electrical stimulation of DLM axons readily activates feedforward inhibition in LMAN in vitro (Livingston and Mooney, 1997). Here, inactivation experiments show that LMAN projection neurons are highly responsive to GABA in vivo and also reveal that occluding GABA receptors in LMAN fails to alter the time course of song-evoked responses. Therefore, in contrast with $\mathrm{HVc}$, where inhibition may sharpen the timing of song-evoked responses (Lewicki, 1996; Mooney, 2000), song-evoked responses in LMAN are not appreciably refined by inhibition. Inhibition in LMAN has been implicated in shaping the responses to nonsong stimuli such as white noise, because responses to these stimuli are seen less frequently in LMAN than in area $\mathrm{X}$ and even then usually involve firing-rate suppression, suggestive of inhibitory influences (Doupe, 1997). The present results show that this firing-rate suppression is accompanied by hyperpolarization in LMAN neurons. The absence of conductance changes associated with this hyperpolarization suggests that it arises via reduced tonic excitatory drive, rather than local inhibition, because GABA-mediated inhibition would be expected to involve a large conductance increase. Additionally, there is a close match between LMAN's subthreshold and suprathreshold tuning to white noise stimuli, indicating that nonlinear mechanisms at the level of single LMAN projection neurons are unlikely to shape these responses. In summary, the present study strongly suggests that LMAN circuitry relays and possibly amplifies highly song-selective auditory afferents, rather than refining less-selective extrinsic inputs.

The present results do show that LMAN local circuitry may act to gate song-evoked responses to RA and area X. First, a subset (53/236) of selective LMAN neurons exhibited only subthreshold responses to song, indicating that not all LMAN neurons transmit song-selective information to their postsynaptic targets. The suppression of spiking in these neurons could reflect a local circuit influence. Second, the local inhibitory circuit is needed to maintain 
a high degree of selectivity in LMAN. Bicuculline treatment induced rhythmic bursting, likely because of disinhibition of a robust recurrent excitatory network formed by the local axon collaterals of LMAN projection neurons (Livingston and Mooney, 1997; Boettiger and Doupe, 1998; Bottjer et al., 1998). In this disinhibited state, song selectivity is dramatically reduced, consistent with intrinsic excitation masking persistently selective extrinsic inputs. Although bicuculline treatment is nonphysiological, endogenous factors that affect inhibitory tone within LMAN could be crucial to gating song-selective information to its postsynaptic targets. Such factors may include neuromodulators, which in the mammalian lateral geniculate nucleus can potently affect inhibitory tone and thus alter the gating of retinal signals to the visual cortex (Pape and McCormick, 1990). In both HVc and RA, song playback-evoked responses can be augmented under certain anesthetics and during sleep, suggestive of neuromodulatory influences on auditory responsiveness. Moreover, direct evidence exists for neuromodulatory gating of these auditory responses; application of norepinephrine to $\mathrm{HVc}$ of anesthetized birds can suppress song-selective responses in $\mathrm{RA}$, while leaving those in $\mathrm{HVc}$ intact (Dave et al., 1998). In LMAN, neuromodulators may also be important for gating song-related auditory information to RA. Candidate neuromodulators include catecholamines, whose regulatory enzymes are developmentally modulated in LMAN (Soha et al., 1996; Mello et al., 1998), which could ultimately affect LMAN's ability to influence RA during sensorimotor learning. In the adult, a behavioral regulator of LMAN excitability that hints at neuromodulatory influences is social context; spontaneous and singing-related electrical activity and activity-dependent gene expression in LMAN strongly depend on whether or not the song is directed toward another bird (Jarvis et al., 1998; Hessler and Doupe, 1999). In states other than those studied here, LMAN may play an active role in shaping song selectivity. For example, birds producing an abnormal song via tracheosyringeal nerve transection exhibit BOS responses in area X but not LMAN (Solis and Doupe, 2000), suggesting that LMAN may gate or mask song-selective afferents. Also, because LMAN neurons display singing-related motor activity (Hessler and Doupe, 1999), it is possible that LMAN's local circuit might modify afferent motor or auditory activity differently in a motor context. Therefore, it will be important to determine whether neuromodulators affect the gating of LMAN's thalamic inputs, for example, by changing inhibitory tone, thus altering LMAN's ability to provide auditory or motor information to RA either during development or in different behavioral contexts.

\section{REFERENCES}

Boettiger CA, Doupe AJ (1998) Intrinsic and thalamic excitatory inputs onto songbird LMAN neurons differ in their pharmacological and temporal properties. J Neurophysiol 79:2615-2628.

Bottjer SW, Miesner EA, Arnold AP (1984) Forebrain lesions disrupt development but not maintenance of song in passerine birds. Science 224:901-903.

Bottjer SW, Halsema KA, Brown SA, Miesner EA (1989) Axonal connections of a forebrain nucleus involved with vocal learning in zebra finches. J Comp Neurol 279:312-326.

Bottjer SW, Brady JD, Walsh JP (1998) Intrinsic and synaptic properties of neurons in the vocal-control nucleus LMAN from in vitro slice preparations of juvenile and adult zebra finches. J Neurobiol 37:642-658.

Brainard MS, Doupe AJ (2000) Interruption of a basal ganglia-forebrain circuit prevents plasticity of learned vocalizations. Nature 404:762-766.

Canady RA, Burd GD, DeVoogd TJ, Nottebohm F (1988) Effect of testosterone on input received by an identified neuron type of the canary song system: a Golgi/electron microscopy/degeneration study. J Neurosci 8:3770-3784.

Dave AS, Yu AC, Margoliash D (1998) Behavioral state modulation of auditory activity in a vocal motor system. Science 282:2250-2254.

Doupe AJ (1997) Song- and order-selective neurons in the songbird anterior forebrain and their emergence during vocal development. J Neurosci 17:1147-1167.

Doupe AJ, Konishi M (1991) Song-selective auditory circuits in the vocal control system of the zebra finch. Proc Natl Acad Sci USA 88: 11339-11343.
Esser KH, Condon CJ, Suga N, Kanwal JS (1997) Syntax processing by auditory cortical neurons in the FM-FM area of the mustached bat Pteronotus parnellii. Proc Natl Acad Sci USA 94:14019-14024.

Ferster D (1986) Orientation selectivity of synaptic potentials in neurons of cat primary visual cortex. J Neurosci 6:1284-1301.

Green DM, Swets JA (1966) Signal detection theory and psychophysics. New York: Wiley.

Hessler NA, Doupe AJ (1999) Social context modulates singing-related neural activity in the songbird forebrain. Nat Neurosci 2:209-211.

Jagadeesh B, Wheat HS, Kontsevich LL, Tyler CW, Ferster D (1997) Direction selectivity of synaptic potentials in simple cells of the cat visual cortex. J Neurophysiol 78:2772-2789.

Jan YN, Jan LY, Kuffler SW (1980) Further evidence for peptidergic transmission in sympathetic ganglia. Proc Natl Acad Sci USA 77:5008-5012.

Janata P, Margoliash D (1999) Gradual emergence of song selectivity in sensorimotor structures of the male zebra finch song system. J Neurosci 19:5108-5118.

Jarvis ED, Scharff C, Grossman MR, Ramos JA, Nottebohm F (1998) For whom the bird sings: context-dependent gene expression. Neuron 21:775-788.

Kittelberger JM, Mooney R (1999) Lesions of an avian forebrain nucleus that disrupt song development alter synaptic connectivity and transmission in the vocal premotor pathway. J Neurosci 19:9385-9398.

Konishi M, Takahashi TT, Wagner H, Sullivan WE, Carr CE (1988) Neurophysiological and anatomical substrates of sound localization in the owl. In: Auditory function: neurobiological bases of learning (Edelman GM, Gall WE, Cowan WM, eds), pp 721-745. New York: Wiley.

Leonardo A, Konishi M (1999) Decrystallization of adult birdsong by perturbation of auditory feedback. Nature 399:466-470.

Lewicki MS (1996) Intracellular characterization of song-specific neurons in the zebra finch auditory forebrain. J Neurosci 16:5855-5863.

Livingston FS, Mooney R (1997) Development of intrinsic and synaptic properties in a forebrain nucleus essential to avian song learning. J Neurosci 17:8997-9009.

Livingstone M, Hubel D (1988) Segregation of form, color, movement, and depth: anatomy, physiology, and perception. Science 240:740-749.

Maekawa M, Uno H (1996) Difference in selectivity to song note properties between the vocal nuclei of the zebra finch. Neurosci Lett 218:123-126.

Margoliash D (1983) Acoustic parameters underlying the responses of song-specific neurons in the white-crowned sparrow. J Neurosci 3:1039-1057.

McCasland JS (1987) Neuronal control of bird song production. J Neurosci 7:23-39.

Mello CV, Pinaud R, Ribeiro S (1998) Noradrenergic system of the zebra finch brain: immunocytochemical study of dopamine-beta-hydroxylase. J Comp Neurol 400:207-228.

Mooney R, Konishi M (1991) Two distinct inputs to an avian song nucleus activate different glutamatergic receptor subtypes on individual neurons. Proc Natl Acad Sci USA 88:4075-4079.

Mooney R (1992) Synaptic basis for developmental plasticity in a birdsong nucleus. J Neurosci 12:2464-2477.

Mooney R (2000) Different subthreshold mechanisms underlie song selectivity in identified $\mathrm{HVc}$ neurons of the zebra finch. J Neurosci

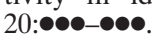

Narins PM, Capranica RR (1976) Sexual differences in the auditory system of the tree frog Eleutherodactylus coqui. Science 192:378-380.

Nordeen KW, Nordeen EJ (1992) Auditory feedback is necessary for the maintenance of stereotyped song in adult zebra finches. Behav Neural Biol 57:58-66.

Nottebohm F, Stokes TM, Leonard CM (1976) Central control of song in the canary, Serinus canarius. J Comp Neurol 165:457-486.

Okuhata S, Saito N (1987) Synaptic connections of thalamo-cerebral vocal nuclei of the canary. Brain Res Bull 18:35-44.

Pape HC, McCormick DA (1990) Ionic mechanisms of modulatory brain stem influences in the thalamus. J Basic Clin Physiol Pharmacol 1:107-117.

Price PH (1979) Developmental determinants of structure in zebra finch song. J Comp Physiol Psychol 93:260-277.

Rauschecker JP, Tian B, Hauser M (1995) Processing of complex sounds in the macaque nonprimary auditory cortex. Science 268:111-114.

Scharff C, Nottebohm F, Cynx J (1998) Conspecific and heterospecific song discrimination in male zebra finches with lesions in the anterior forebrain pathway. J Neurobiol 36:81-90.

Simpson HB, Vicario DS (1990) Brain pathways for learned and unlearned vocalizations differ in zebra finches. J Neurosci 10:1541-1556.

Soha JA, Shimizu T, Doupe AJ (1996) Development of the catecholaminergic innervation of the song system of the male zebra finch. J Neurobiol 29:473-489.

Solis MM, Doupe AJ (1997) Anterior forebrain neurons develop selectivity by an intermediate stage of birdsong learning. J Neurosci 17:6447-6462.

Solis MM, Doupe AJ (2000) Compromised neural selectivity for song in birds with impaired sensorimotor learning. Neuron 25:109-121.

Theunissen FE, Doupe AJ (1998) Temporal and spectral sensitivity of 
complex auditory neurons in the nucleus $\mathrm{HVc}$ of male zebra finches. J Neurosci 18:3786-3802.

Vates GE, Nottebohm F (1995) Feedback circuitry within a song-learning pathway. Proc Natl Acad Sci USA 92:5139-5143.

Vates GE, Broome BM, Mello CV, Nottebohm F (1996) Auditory pathways of caudal telencephalon and their relation to the song system of adult male zebra finches. J Comp Neurol 366:613-642.

Vicario DS (1991) Organization of the zebra finch song control system. II. Functional organization of outputs from nucleus robustus archistriatalis. J Comp Neurol 309:486-494.

Vicario DS, Yohay KH (1993) Song-selective auditory input to a forebrain vocal control nucleus in the zebra finch. J Neurobiol 24:488-505.
Wild JM (1993a) The avian nucleus retroambigualis: a nucleus for breathing, singing and calling. Brain Res 606:319-324.

Wild JM (1993b) Descending projections of the songbird nucleus robustus archistriatalis. J Comp Neurol 338:225-241.

Williams H, Mehta N (1999) Changes in adult zebra finch song require a forebrain nucleus that is not necessary for song production. J Neurobiol 39:14-28.

Williams H, Nottebohm F (1985) Auditory responses in avian vocal motor neurons: a motor theory for song perception in birds. Science 229:279-282.

Yu AC, Margoliash D (1996) Temporal hierarchical control of singing in birds. Science 273:1871-1875. 